\title{
P32-06＼cjkstart超小型ガスタービン用遠心圧縮機の要素試作
}

\section{Design and Fabrication of Centrifugal Compressor for Ultra Micro Gas Turbine}

\section{○山口 直樹（法政大院）田中 伸佳（日本航空）水木 新平（法政大）}

御法川 学 (法政大) 太田 有 (早稲田大) 大田 英輔（早稲田大）

\author{
Naoki YAMAGUCHI, Hosei University, 3-7-2, Kajino-cho, Koganei, Tokyo \\ Nobuyoshi TANAKA, Japan Air Lines \\ Shimpei MIZUKI, Hosei University \\ Gaku MINORIKAWA, Hosei University \\ Yutaka OHTA, Waseda University, 3-4-1, Oukubo, Shinjuku-ku, Tokyo \\ Eisuke OUTA, Waseda University
}

\begin{abstract}
An impeller was designed and manufactured in order to use for an ultra micro gas turbine. As the first stage of the design, the impeller with two-dimensional backward curved blades was designed and manufactured by an ordinary one-dimensional method.

The major parameters such as the relative velocity ratio, velocity triangles, pressure recovery coefficient of the vaned diffuser were chosen at the same values for those of three-dimensional impellers. The preliminary test of the impeller was made at the low rotational speed by the cold condition of the driving turbine.
\end{abstract}

Key Words: Centrifugal compressor, Ultra micro gas turbine, Performance characteristics, Two dimensional impeller

\section{1.はじめに}

遠心圧縮機は古くより産業用、航空用、車両用など幅広 く使用されて来ており、また、車両用ターボチャージャーに 使用されるようになってから、生産台数も飛躍的に増加して いる。このような背景からその設計および製造技術はかなり 確立されていると考えることが出来る。

一方、近年、電力用の分散型エネルギー源などにはじまり、 モバイル電源や超小型飛行機用を目指したガスタービンの 小型化に対する研究や試作が盛んに試みられている。 ここでは超小型ガスタービン用を考えた超小型遠心圧縮機 を設計、製作し、要素テストを試み、その結果を報告する。

\section{2. 設計}

超小型圧縮機については既に幾つかの報告があるが.(例え ば文献 ${ }^{1)}$ (4) 、羽根車が 2 次元形状のものと 3 次元形状のも のがある。設計が 2 次元から擬 3 次元、 3 次元と高度化する につれて性能特性が向上することは良く知られているが 5)、

(図 1-1, 図 1-2) 一方、超小型化のためには製作が非常 に難しくなってくる。

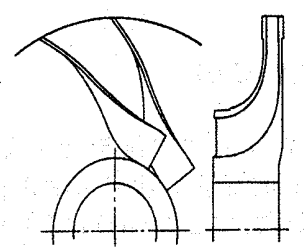

(a) インデューサ付 3 次元羽根車 (3DI)

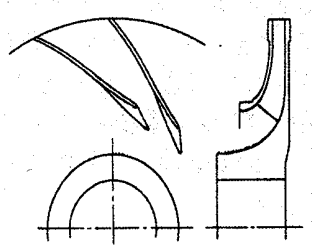

(c) 擬 3 次元羽根車 (Q3D)

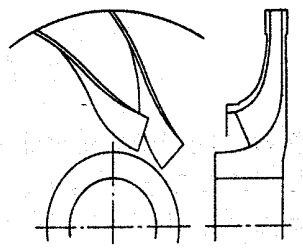

(b) 3 次元羽根車

(3D)

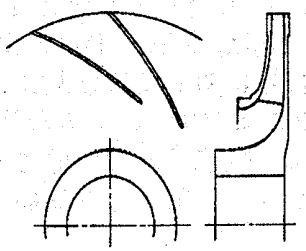

(d) 2 次元羽根車

(2D)
図 1-1 4 種類の羽根車 ${ }^{5}$

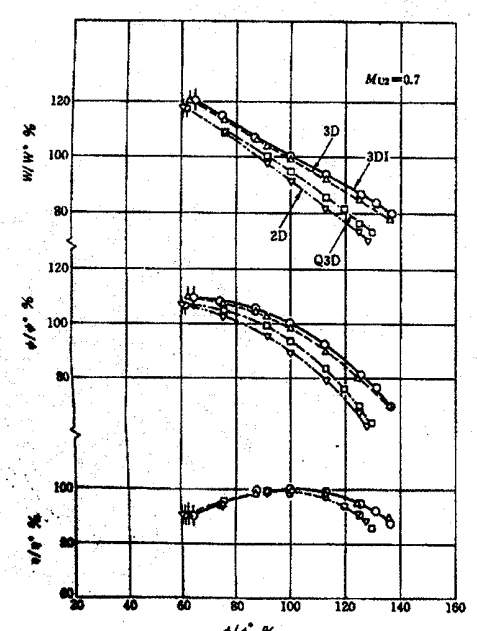

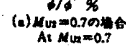

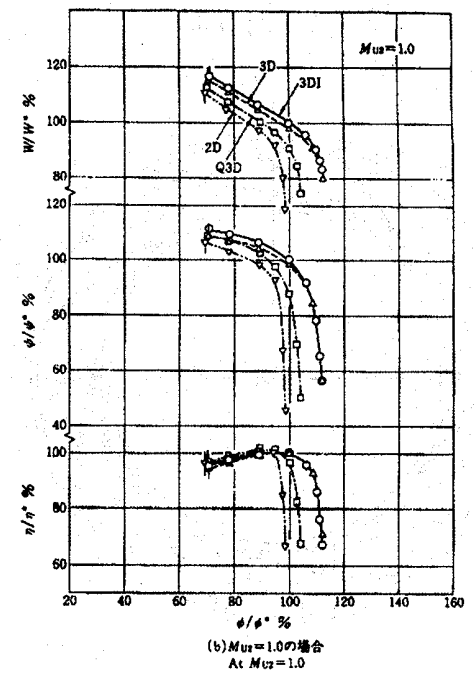

図 1-2 無次元特性 ${ }^{5)}$ 
本研究では超小型化の第一段階として、10 倍モデルを対 象にしているのでこの大きさでは 3 次元形状が十分可能で あり、さらに小型化しても既存の設計技術で十分に対応出来 ると考え、はるかに小型化された場合を想定して 2 次元形状 を選択した。羽根車を小型化した場合のレイノルズ数を代表 寸法に外径を、速度に周速度を取って考えて見る。周速度を 取った理由は周速度により圧力比がおおよそ決まり、また、 羽根車入口と出口の相対速度と周速度の比にはある一定の 関倸が存在し、さらに相対速度比には最適值が存在すること による。どのように小型化しても全圧力比を約 3 としている ので 周速度はあまり変化できない。

一方、羽根車外径は $1 / 10$ になるとするとレイノルズ数は 同じく $1 / 10$ となる。従って、小型化に比例してレイノルズ 数は減少する。反対に加工粗さを考えると、加工方法によっ て達成できる最小の粗さは決定される。即ち、代表寸法に対 する相対粗さは寸法に逆比例して増加する。例えば Moody 線図を考えると、摩擦による損失は増加して、壁面摩擦損失 および円板摩擦損失が必ず増加する。さらに 2 次元羽根であ るから羽根車入口の子午面の急激な曲がりによって はく りによる損失が生じる。また、2 次元羽根であるから衝突損 失は設計点でも無衝突となる位置以外で生じ、設計点以外で は さらに大きくなる。羽根車間隙損失の間隙自体を小型化 により小さく取ることは困難で 羽根車出口の羽根高さ比 で 10 パーセント程度になると推測できる。

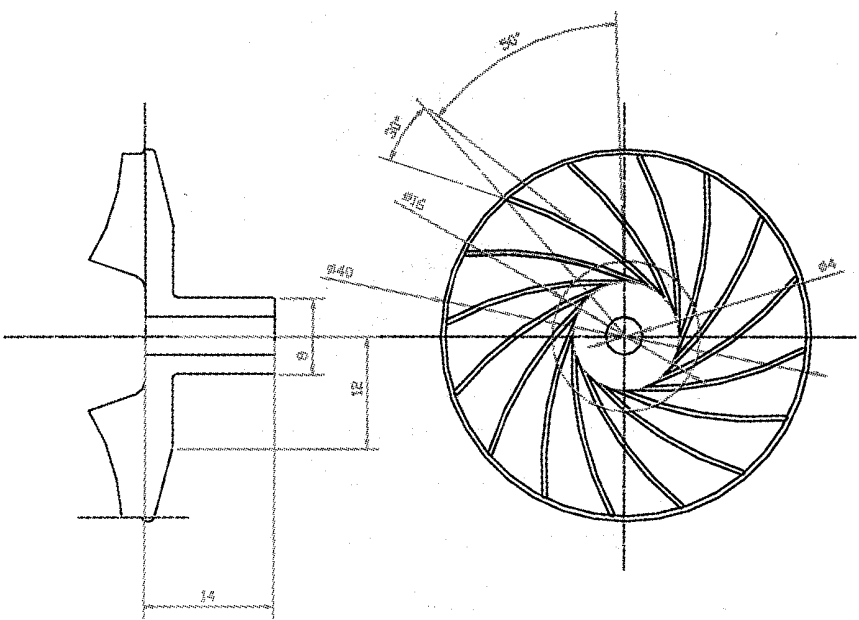

図 2-1：羽根車

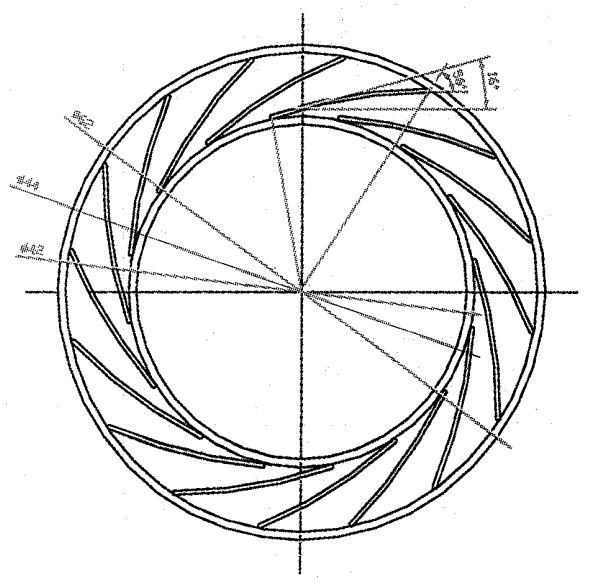

図 2-2 ディフューザ
以上のような点を考慮し、図 1-1 $1^{5}$ および図 1-25)に示す 結果を参考にすると 本羽根車は 3 次元形状のものに対し て、達成できうる効率もかなり低く、また、作動範囲もかな り狭くなることが実験するまでもなく確実に予想できる。従 つて、このような 2 次元羽根のメリットは製作が簡単である ことだけになるが、これをべースとしてより高い効率と広い 作動範囲を達成させる試みがこれからの大きな課題と考え られる。また、既存のデータベースによる設計法が適用でき なくなり、新たなデータの蓄積が必要となると考えられる。

設計された羽根車およびディフューザ形状を図 2-1およ び図 2-2 に示す。設計に際しては、インデューサ衝突損失、 壁面摩擦損失、2 次流れ損失、漏れ損失、混合損失、円板摩 擦損失およびディフューザでのブロッケージと压力回復率 などを考慮し、すべり係数には Wiesnerの式を用いた ${ }^{6)}$ 。圧 縮機各要素の入口と出口の全圧力、静圧力、相対速度、絶対 速度および流れ角、温度などを検討し、形状の修正は非常に 容易である。さらに予備計算として CFD を用い、とくに羽 根車入口で予想通り強いはくりが生ずることも確かめられ た。図 3 には羽根車入口部分の子午面内翼面中央での速度べ クトルを示す。計算を簡便に行うために、羽根車入口部分は スパン方向に直線形状となっている。羽根先端、シュラウド 側に大きな剥離による渦が認められる。

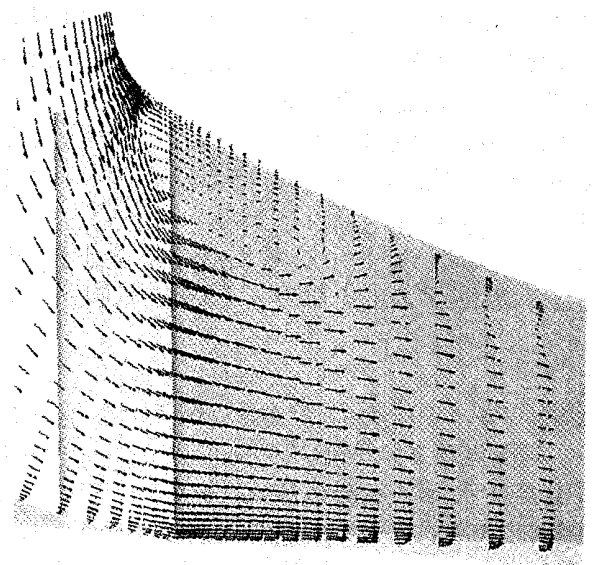

図 3 子午面形状の CFD

参考に性能予測法により得られたマップの例を図 4 に示 した。ここで $\pi$ は全圧力比、 $\mathrm{G}$ は重量流量で効率も示されて いる。設計点において予測した回転数は 220000 rpm であり、 流量は $0.033 \mathrm{kgf} / \mathrm{s}$ で入口と出口の相対速度比は 0.68 である。 ここで用いた性能予測法 ${ }^{6}$ )では壁面摩擦係数などの仮定さ れた定数などを変化させたりすると結果に大きな相違が生 じ、また、3 次元形状のより外径の大きいインデューサ付き 羽根車に対して実験結果と一致するようになっているので、 図 2 および図 4 のような構成要素からなる圧縮機に対しては 正確な性能予測は困難であると考えられる。羽根車およびデ イフューザの主要な緒元を表 1 に示す。 
表 1 圧縮機の設計仕様

\begin{tabular}{|c|c|c|}
\hline \multirow{9}{*}{ 羽根車 } & 入口直径 $[\mathrm{mm}]$ & 20 \\
\hline & 出口直径[mm] & 40 \\
\hline & 羽根枚数 & 16 \\
\hline & 羽根厚 $[\mathrm{mm}]$ & 0.5 \\
\hline & 入口羽根高さ[mm] & 6.05 \\
\hline & 出口羽根高さ[mm] & 2.4 \\
\hline & 羽根入口角度 ${ }^{\circ}$ ] & 50 \\
\hline & 羽根出口角度 $\left[^{\circ}\right.$ ] & 30 \\
\hline & 出口流れ角 $\left.{ }^{\circ}\right]$ & 76 \\
\hline \multirow{5}{*}{ ディフューザ } & 入口直径 $[\mathrm{mm}]$ & 42 \\
\hline & 出口直径 $[\mathrm{mm}]$ & 60 \\
\hline & 羽根枚数 & 16 \\
\hline & 羽根厚さ[mm] & 0.5 \\
\hline & 羽根高さ[mm] & 2.4 \\
\hline
\end{tabular}
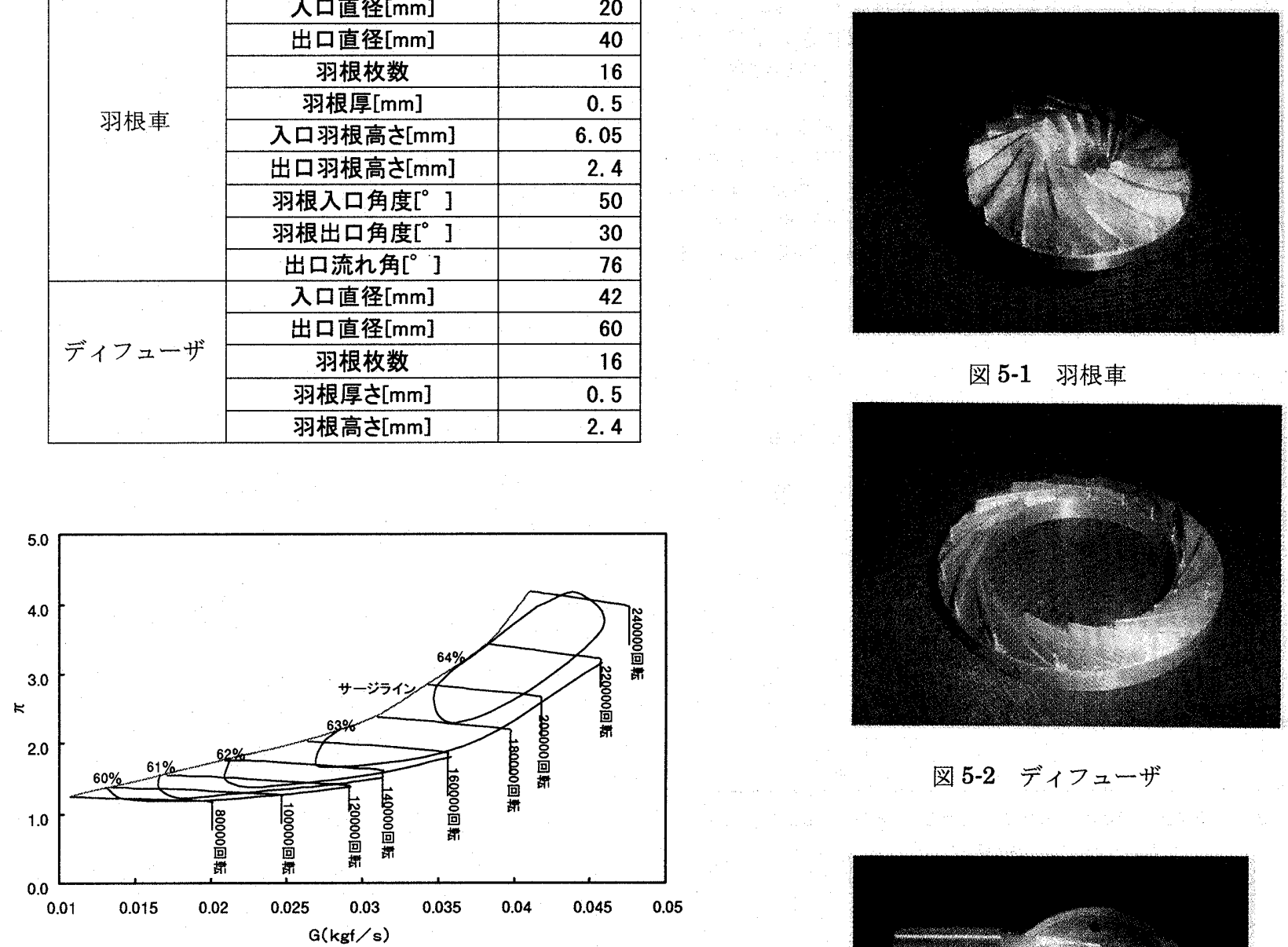

図 5-1 羽根車

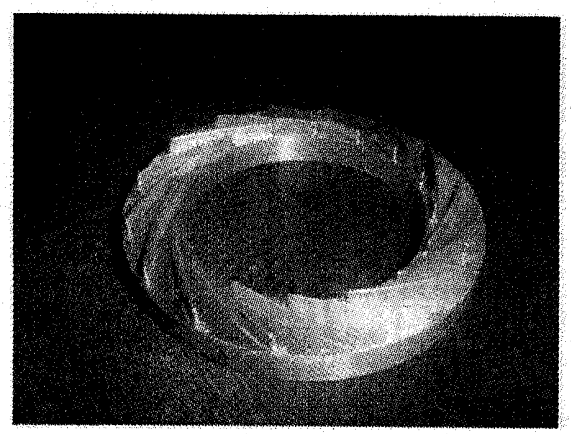

図 5-2 ディフューザ

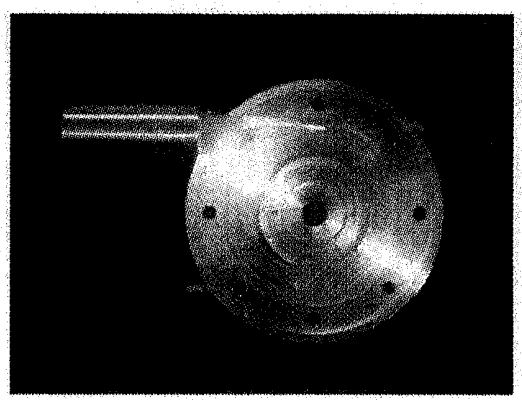

図 5-3 ケーシング

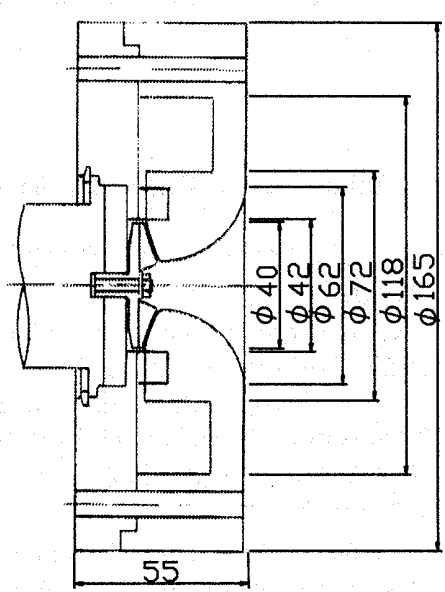

図 6 圧縮機組立断面図 


\section{4. 実験結果および考察}

実験はコールドテストのため、設計点よりはるかに低い $50,000 \mathrm{rpm}$ で行った。図7に羽根なしと羽根付きディフュー ザの場合の測定結果を示す。当然のことながら羽根付きディ フューザの場合が作動範囲は狭いが、設計点で高い全圧力比 が得られた。これらの結果を性能予測による結果(図 4)と対 比する。図 4 では 50,000 rpmにおける性能曲線は明示してい ないが、流量および圧力がやや低く出ているものの、定性的 には一致しており、効率は $60 \%$ 程度であると推察される。 なお、設計に用いた性能予測法による結果は、実験による結 果とかなり相違したため、ここでは除外した。

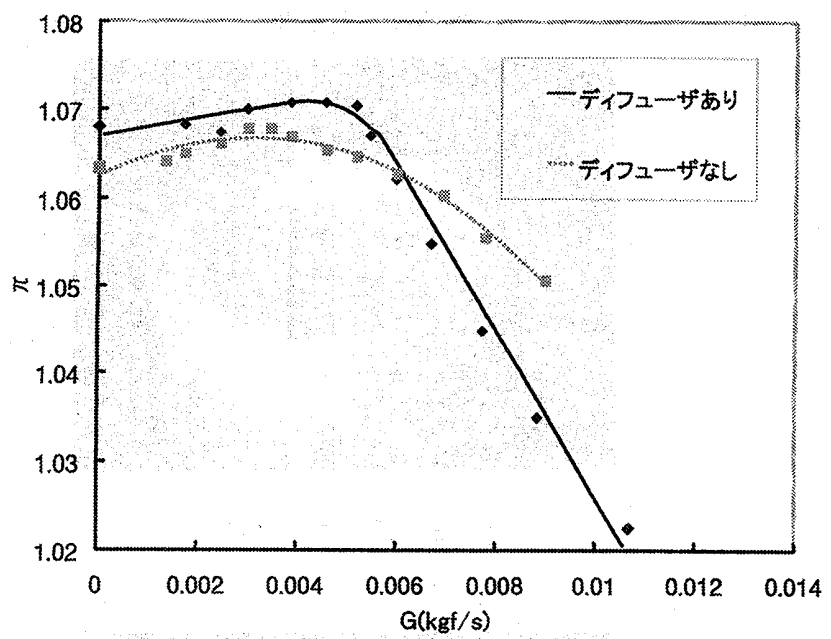

図 7 実験結果

\section{5.おわりに}

予定よりかなり遅れたため、全く初期の予備実験結果だけ しか報告できない。燃焼テストの淮備が整い次第、ケーシン グトリートメントなどを含めた、より高効率で広い作動範囲 を目指した試験を行い、設計指針の確立を図りたい。

本研究開発は、NEDOの平成 13 年度エネルギー・環境国際 共同研究提案公募事業「ボタン型ガスジェネレータ実用化 技術開発」を東京大学生産技術研究所が受託し，その一貫 として行われたものである.

参考文献

(1)S. Ashley, Turbine on a Dime, Mechanical Engineering, 1997-10

(2)日本ガスタービン学会誌・マイクロガスタービン特集 号,Vol.29,No.3,2001-5

(3)S. Tanaka et.al., Design and Fabrication Challenges for Micromachined Gas Turbine Generators, 9th ISROMAC,2002-2

(4)K. Isomura et.al., Design Study of a Micromachined Gas Turbine with 3-Dimentional Impeller, 9th ISROMAC,2002-2

(5)安斉章他、高性能遠心圧縮機の設計システム、エバラ時報、 No.146,pp.27-35,1990

(6)Michael R. Galvas, Analytical Correlation of Centrifugal Compressor Design Geometry for Maximum Efficiency with Specific Speed, NASA TN D-6729, (1972) 